\title{
Research on the development of hierarchical teaching in College Mathematics Teaching
}

\author{
Li pingDing \\ School of science,Xi'an University of Architecture and Technology ,Xi'an, Shaanxi,PR \\ China, 710055
}

Key words: College mathematics; hierarchical teaching; teaching significance

\begin{abstract}
Mathematics is not only a very important subject in basic teaching, but also an important part of College teaching. Colleges and universities should pay attention to the corresponding teaching methods in the process of mathematics teaching, through the application of a variety of teaching methods to achieve better teaching results. Layered teaching is one of the most important teaching methods, which make the development of mathematics teaching activities more targeted, so that the development of teaching activities more effective. Take into account this, this article carries on the analysis research to the university mathematics teaching stratification teaching carries on the analysis, provides the reference. The math is always very important in the teaching of college teaching subjects, which not only can effectively cultivate students' mathematical thinking, but also to let students through learning math knowledge to achieve a better life to solve the problem of utility. In the process of mathematics teaching, through the application of hierarchical teaching method can effectively achieve the purpose of teaching, make students learning objectives more clearly, to help students learn through the concept and thought of learning and penetration. Therefore, the teacher should give a deep study on the hierarchical teaching method, and make it play a more important role in the college mathematics teaching.
\end{abstract}

\section{Introduction}

Hierarchical teaching is also known as grading teaching, according to the level of the students and the existing teaching resources, students will be divided into different levels, according to different levels of students, different formulation of the teaching goal, so as to realize the optimization of teaching plan, scheme, method, and implement the principle of individualized teaching. The implementation of hierarchical teaching, so that the limitations of the traditional class teaching system is broken, is conducive to the realization of students' self promotion. As a teacher, we must grasp the students' learning situation, individual differences in teaching should not only respect the students, but also pay attention to the development of students' personality, according to the present situation of the students, make corresponding adjustments to the teaching schedule, to meet the development needs of students, which can make the teaching effect is improved obviously. [1]

\section{The significance of higher mathematics teaching method}

In Colleges and universities in the teaching of higher mathematics, the use of hierarchical teaching method for mathematics teachers' teaching idea renewal, the traditional mathematics teaching, teachers are the main body of the class, dominate the whole class, the students just passively accept, teacher-student interaction is less, the contradiction between the teaching and learning more 
prominent, and the implementation of hierarchical teaching method, the the students as the main body of the class, give full play to their main role, teachers play the main role is to guide and help students autonomous learning ability, at the same time, the teacher teaching is more targeted, contribute to the improvement of students' scores. The same students divided into a class, teaching content is highly targeted, more positive, active classroom atmosphere, students can actively participate in the discussion, to help them improve their self-confidence, can quickly achieve on their own position, to help them build a relatively complete system of mathematics knowledge, make them the quality of mathematics learning is improved obviously. The development of the mathematics course in Colleges and universities can not be separated from the application of the hierarchical teaching method, which can not be separated from the role of the hierarchical teaching method. [2]

\section{The teaching of mathematics teaching in Colleges and Universities}

In mathematical teaching, each student is an independent individual, their level of knowledge and ability between different, there is a larger difference, if these students are unified teaching, will make the comprehensive strength of the level of disagreement, have serious differentiation, this will continue to increase the gap between college students that led to the formation of a growing distance between students. The use of hierarchical teaching method, the students will be split into different levels, division is the basis of the difference between them, can be of interest, can also be the quality and so on, there are a lot of standard. For example, teachers can be subdivided into A, B, $\mathrm{C}$ three levels according to the student's self-evaluation or comprehensive performance. Classification of students, with many kinds of methods, not only one, and the hierarchical management of students, not a fixed process, it is a dynamic process, is constantly developing and changing, which means in different teaching period and stage level students that is likely to change, it will be accompanied by the development of the students and change accordingly, so the hierarchical teaching raises a higher demand on teachers, teachers must understand all aspects of students, students have a good understanding, can grasp the overall situation of the students, only in this way in order to ensure the rationality and scientificalness and feasibility of grading students. [3]

Teachers' lesson preparation is the most important part in teaching activities, and plays an important role in the entire teaching process. In traditional mathematics class teaching, teacher preparation is to prepare a lesson, lesson plans which record the teaching purpose, teaching difficulties, class, teaching steps, Blackboard design and so on, the plan is for all students. Different from the traditional teacher preparation, teaching process, teachers must fully grasp and understand the teaching material, and on this basis, according to the different levels of students, to write the teaching plans, students is based on the one hand, and divided into A, B, C three different levels the actual situation of the students of different levels are different, which is suitable for students preparing lesson plans are different, there are also obvious differences. This requires that teachers should according to the actual situation of students of different levels, to write out different teaching plans, and the actual situation and students should be relative, for example when writing exercises and examples on the teaching plans, the students of different levels, understanding of the issues and the degree is not the same, they the problem solving ability also has the obvious difference, this requires teachers to determine the exercises, examples of the difficulty level according to the student's level, to ensure compliance with the level of students, so as to let students get improved in their original basis, and comprehensively improve the level of student learning, so they get a holistic development the. [4]

In mathematics teaching, students will be divided into different levels, between the various 
levels of the students, there are obvious differences, differences in many aspects of knowledge, the same content, different levels of students, understand and accept it is different, their ability is different, in need, in in the classroom teaching, to students as the main body of the class, give full play to their main role, teachers in the teaching process, play a guiding role to play the guiding role of teachers, in the process of teaching methods selection, teachers should pay attention to break the traditional restrictions, using a variety of methods the teaching way, make it better serve their teaching methods, through the application of different teaching methods, to meet the needs of students at different levels, so that different levels of The students have been improved, make certain progress, enable them to experience the process of learning achievement, to meet the needs of certain aspects of them, to attract their interest in learning, so as to achieve the purpose of teaching. [5]

Teaching evaluation is a process of evaluating teaching achievement and teaching behavior, which involve not only the realization of teaching objectives, but also the rationality and rationality of the evaluation methods and results. So, to improve the teaching content and teaching method, teachers to improve teaching quality, we must take the scientific teaching evaluation of the teaching evaluation as the basis, the success depends largely on the scientific evaluation methods and scientific evaluation method is not conducive to the success of teaching evaluation. In the teaching of college mathematics, the last step is teaching evaluation, because the hierarchical teaching is students will be divided into different levels, different levels of students, so the knowledge ability and level is different, and in different levels of students evaluation, the standard should be is different, there should be a difference. In the process of teaching, teachers should pay attention to the process of teaching, highlight the key process, focusing on the development of students, in determining the evaluation standards, to fully on the basis of students of different levels to determine the level of difference, make the evaluation in teaching and promote the development of the role into full play. For example, in order to highlight the progressive aspects of learning, a students evaluation standard, should be very strict to the students of the B class, do not need too strict, so that they learn to ease the pressure, appropriate to relax, to the $\mathrm{C}$ students, the key is to encourage them to continue to progress in the evaluation process, we must to avoid the mutual evaluation of students of different levels, to avoid B, C level students inferiority complex. [6]

In the hierarchical teaching of mathematics, students will be divided into different levels, not free, in order to enable students to avoid unnecessary psychological burden, when teachers were stratified to students, must be based on the actual situation of the students, are fully considered on their psychological features, we must respect the students' main body the status, give full play to their main role, pay attention to what in strict accordance with the democracy, the principle of subjectivity, and teachers are not autocratic, must respect the wishes of the students, will choose the classification of teachers and students together, to achieve the students of different levels. If the student hierarchy process, students and teachers will appear inconsistent classification situation, at this time, teachers can not be stubborn, should stand in the position of students for students to consider, pay attention to the role of subjectivity and the principles of democracy, without special circumstances, teachers should try to adopt the views of students and respect the students' intention to avoid because of the hierarchical teaching have bad effects on students, affect students' knowledge and ability.

Hierarchical teaching is a dynamic process of teaching, there are individual differences, between different students at the same time, each student is a development of the individual, with the impact of the external environment and their own factors, students are constantly in change, which means to the layer of students is not fixed there is a certain variability, with the development 
and progress of them, and produce a corresponding change, which requires, in the hierarchical teaching of mathematics, according to students' progress, hierarchical levels of students make the appropriate changes and adjustments, so that students at a level, for their own actual situation, the whole process of mathematics teaching, looking forward to the continuous development and progress, to get the whole promotion. In specific classroom teaching activities, teachers in the evaluation of students, should pay attention to the development of evaluation from the dynamic, for example, teachers can help students to set up a small goal, this goal must be feasible, and is a short period of time can be achieved, through continuous implementation of these small targets. To enable students to obtain a sense of satisfaction and achievement, prompting them to move to a higher level, to help them achieve greater development and progress. Through the way of setting up the target step by step, the students' learning burden can be reduced.

The students"s self cognition and self-evaluation are two different aspects, but there is a close relationship between the two. Only students in the full understanding of self, face up to the problems the existence of positive ability, and can timely correct for it, which can promote students' autonomous learning ability to continuously improve, help them develop and build good personality, promote the development of all aspects of their ability, so that they continue to make progress, is conducive to their overall promotion. In the teaching process of college mathematics, not only for students in the period or the final exam, to determine their level of increase or decrease, decided to change the level of students, should not just mid-term or final results, this is too one-sided not only difficult to stimulate students' learning enthusiasm. The division of the student level is not fair, must pay attention to the combination of students' usual classroom performance, because the results do not represent all the more ability, can not fully explain the specific circumstances of the students, but also not conducive to students' self cognition. And sometimes result in classroom performance and there are many different, the two are not completely proportional to the teachers can be based on students' self-evaluation, appropriate to remind students of proposed change in the level of application, teachers can also, usually pay more attention to the students, to understand students' development, according to the dynamic change in a certain period of time they encourage students to put forward the application upgrade. [7]

\section{Conclusion:}

Stratified teaching has some discussion in the traditional teaching process, the experience in the development and evolution, growing with the times, and play a greater role in the classroom teaching, and through targeted application achieved better teaching effect. Teachers should be in-depth study and analysis of the hierarchical teaching, let it play a greater role in the field of mathematics teaching, let it play a greater role in the training of mathematics successors, make it become an important path of mathematics talents trained, make it become an important auxiliary method for research of mathematical problems.

\section{References:}

[1]Johnson R A. Recent Publications: Reviews: A Critical Study of the Teaching of Elementary College Mathematics.[J]. Progress in Organic Coatings, 2008, 63(4):399-404.

[2]Li A, Long J, Tao G, et al. Research on the Inquiry Teaching Model of Men's Basketball Teaching in College Physical Education based on Network Information Technology[J]. International Journal of Smart Home, 2015, 9(10):169-178.

[3]Joly M, Rocha R, Sousa L C F, et al. The strategic importance of teaching Operations Research 
for achieving high performance in the petroleum refining business[J]. Education for Chemical Engineers, 2015, 10:1-19.

[4]Lynda R. Wiest. The Role of Computers in Mathematics Teaching and Learning[J]. Computers in the Schools, 2001, 17(1-2):41-55.

[5]Foshee C M, Elliott S N, Atkinson R K. Technology-enhanced learning in college mathematics remediation[J]. British Journal of Educational Technology, 2016, 47(5):893-905.

[6]Deng X, Qiang Z, Zhao Q, et al. Effects of architectures and H 2 O 2, additions on the photocatalytic performance of hierarchical $\mathrm{Cu} 2 \mathrm{O}$ nanostructures[J]. Nanoscale Research Letters, 2015, 10(1):8.

[7]Sun B, Li L, Wu X, et al. Combining feature-level and decision-level fusion in a hierarchical classifier for emotion recognition in the wild[J]. Journal on Multimodal User Interfaces, 2016, 10(2):125-137. 